\title{
Reproductive factors and subtypes of breast cancer defined by hormone receptor and histology
}

\section{G Ursin*,1,2, L Bernstein', SJ Lord', R Karim', D Deapen', MF Press ${ }^{3}$, JR Daling4, SA Norman ${ }^{5}$, JM Liff', PA Marchbanks ${ }^{7}$, SG Folger ${ }^{7}$, MS Simon ${ }^{8}$, BL Strom ${ }^{5}$, RT Burkman', LK Weiss ${ }^{10}$ and R Spirtas ${ }^{11}$}

'Department of Preventive Medicine, Keck School of Medicine, University of Southern California/Norris Comprehensive Cancer Center, Los Angeles, CA, USA; ${ }^{2}$ Department of Nutrition Research, University of Oslo, Oslo, Nonway; ${ }^{3}$ Department of Pathology, Keck School of Medicine, University of Southern Califormia, Los Angeles, CA, USA; ${ }^{4}$ Division of Public Health, Fred Hutchinson Cancer Research Center and Department of Epidemiology, School of Public Health and Community Medicine, University of Washington, Seattle, WA, USA; ${ }^{5}$ Center for Clinical Epidemiology and Biostatistics and Department of Biostatistics and Epidemiology, University of Pennsylvania, Philadelphia, PA, USA; 'Department of Epidemiology, Rollins School of Public Health, Emory University, Atlanta, GA, USA; ${ }^{7}$ Division of Reproductive Health, Centers for Disease Control and Prevention, Atlanta, GA, USA; ${ }^{8}$ Department of Internal Medicine, Karmanos Cancer Institute at Wayne State University, Detroit, MI, USA; ${ }^{9}$ Department of Obstetrics and Gynecology, Baystate Medical Center, Springfield, MA, USA; ${ }^{10}$ Cancer Centers Branch, National Cancer Institute, Bethesda, MD, USA; " Contraception and Reproductive Health Branch, Center for Population Research, National Institute of Child Health and Human Development, NIH, DHHS, Bethesda, MD, USA

Reproductive factors are associated with reduced risk of breast cancer, but less is known about whether there is differential protection against subtypes of breast cancer. Assuming reproductive factors act through hormonal mechanisms they should protect predominantly against cancers expressing oestrogen (ER) and progesterone (PR) receptors. We examined the effect of reproductive factors on subgroups of tumours defined by hormone receptor status as well as histology using data from the NIHCD Women's Contraceptive and Reproductive Experiences (CARE) Study, a multicenter case-control study of breast cancer. We estimated odds ratios (ORs) and 95\% confidence intervals (Cls) as measures of relative risk using multivariate unconditional logistic regression methods. Multiparity and early age at first birth were associated with reduced relative risk of $E R+P R+$ tumours $(P$ for trend $=0.000 \mathrm{I}$ and $0.0 \mathrm{I}$, respectively), but not of ER-PR - tumours ( $P$ for trend $=0.27$ and 0.85 ), whereas duration of breastfeeding was associated with lower relative risk of both receptor-positive $(P$ for trend $=0.0002)$ and receptor-negative tumours $(P=0.0004)$. Our results were consistent across subgroups of women based on age and ethnicity. We found few significant differences by histologic subtype, although the strongest protective effect of multiparity was seen for mixed ductolobular tumours. Our results indicate that parity and age at first birth are associated with reduced risk of receptor-positive tumours only, while lactation is associated with reduced risk of both receptor-positive and -negative tumours. This suggests that parity and lactation act through different mechanisms. This study also suggests that reproductive factors have similar protective effects on breast tumours of lobular and ductal origin.

British Journal of Cancer (2005) 93, 364-37I. doi:I0.1038/sj.bjc.66027I2 www.bjcancer.com

Published online 2 August 2005

(c) 2005 Cancer Research UK

Keywords: breast cancer; reproductive factors; hormone receptors; histology

The epidemiologic evidence that reproductive factors such as number of full-term pregnancies, age at first full-term pregnancy and duration of breastfeeding are strongly predictive of breast cancer risk is substantial (Kelsey et al, 1993; Collaborative Group on Hormonal Factors in Breast Cancer, 2002). We recently confirmed these findings in the Women's Contraceptive and Reproductive Experiences (CARE) Study and showed that these effects are similar in African-American and White women (Ursin et al, 2004).

*Correspondence: Dr G Ursin, Department of Preventive Medicine, Keck School of Medicine, University of Southern California/Norris Comprehensive Cancer Center, I44I Eastlake Ave, Los Angeles, CA 90089, USA; E-mail: gursin@usc.edu

Received 6 January 2005; revised 13 June 2005; accepted 20 June 2005; published online 2 August 2005
Both multiparity and age at first pregnancy may exert their protective effects on breast cancer through hormonal mechanisms (Bernstein et al, 1985; Garcia-Closas et al, 2002), either through direct action on sex steroids or through hormone-induced breast cell differentiation (Russo et al, 1992). The protective effects of lactation may occur because of both hormonal (Petrakis et al, 1987; Russo and Russo, 1994) and nonhormonal mechanisms (Murrell, 1991). It has previously been proposed that hormonal breast cancer risk factors ought to be predominantly associated with tumours that express oestrogen (ER) and progesterone (PR) receptors, and less so with receptor-negative tumours (McTiernan et al, 1986; Stanford et al, 1987; Potter et al, 1995; Enger et al, 2000; Ursin et al, 2002). However, the studies that have addressed the effect of reproductive factors on breast tumours of different receptor status have yielded mixed results (Hildreth et al, 1983; McTiernan et al, 1986; Stanford et al, 1987; Cooper et al, 1989; 
Potter et al, 1995; Yoo et al, 1997; Huang et al, 2000; Britton et al, 2002; Cotterchio et al, 2003).

The histology of the tumour may complicate this picture even further. It has been hypothesised that lobular cancers may be more strongly associated with certain hormonal risk factors such as postmenopausal hormone therapy use (Li et al, 2000; Daling et al, 2002). However, this has not been found in all studies (Ursin et al, 2002), and there is some evidence that early age at menarche, late age at menopause and obesity are more strongly associated with ductal tumours than lobular tumours (Li et al, 2003).

Tumour histology may also be related to receptor status. Lobular tumours are more often receptor positive than ductal tumours (Chu and Anderson, 2002), and it would therefore seem obvious that overall, lobular tumours should be associated with hormonal factors, but once receptor status has been taken into account, it is not clear whether any of the histological subtypes should be more or less associated with hormonal factors.

We combine epidemiological data with data from pathology reports of cases who participated in the Women's CARE Study to examine the relationships of reproductive factors with different types of breast tumours to gain insight into mechanisms that may be operating. If parity and breastfeeding act through hormonal mechanisms, we expect that they will protect predominantly against tumours that express ER and PR (ER + PR + tumours), while if they act through a nonhormonal mechanism, they will be associated with hormone receptor-positive and -negative tumours to an equal extent.

We also evaluate the associations between reproductive factors and development of tumours of different histologies in all women combined as well as by ERPR status.

\section{MATERIAL AND METHODS}

The Women's CARE Study is a population-based case-control study of breast cancer designed to address the role of reproductive, contraceptive and lifestyle factors on the breast cancer risk of White and African-American women ages 35-64 years in five US regions (Atlanta, Seattle, Detroit, Philadelphia and Los Angeles). The design and methods of this study have previously been described in detail (Marchbanks et al, 2002).

\section{Cases}

Case patients were diagnosed with pathologically confirmed invasive breast cancer between July 1994 and April 1998, and were identified by the Surveillance, Epidemiology and End Results (SEER) cancer registries in Atlanta, Seattle, Detroit and Los Angeles, or from hospitals in Philadelphia. We restricted eligibility to US-born English-speaking women. We oversampled younger case patients and African-American case patients to maximise their numbers in the study, and we randomly sampled older White case patients to achieve approximately equal numbers of case patients in each 5-year age group. Of the 5982 eligible case patients, we interviewed 4575 (76.5\%), including 2953 White patients and 1622 African-Americans.

\section{Controls}

Control subjects were randomly selected from a pool of eligible women identified through random digit dialling (RDD) identified between July 1994 and June 1998. They were US-born Englishspeaking women who had never been diagnosed with invasive or in situ breast cancer. Control subjects were frequency matched to case patients by study centre, race and 5-year age group. We successfully screened $82 \%$ of residential households called. Of the 5956 eligible women selected as control subjects, we interviewed
4682 (78.6\%), including 3021 White subjects and 1661 African Americans.

\section{Data collection}

Risk factor information was obtained from an in-person interview using a structured questionnaire that included questions on demographics, reproductive history (including breastfeeding), medical history including use of exogenous hormones, family history of cancer and other lifestyle factors. Information was recorded up to the date of diagnosis (month and year) for case patients or the date of initial household contact by RDD for control subjects. All cases and controls were interviewed between September 1994 and December 1998. Informed consent was obtained from all participants. Study protocols were approved by the Institutional Review Board at each participating centre.

\section{Receptor status}

Oestrogen receptor and PR status of case patients was recorded from the pathology record when available at each study centre. All SEER registries routinely collect this information for breast cancer, specifically they collect the laboratory results recorded in the medical records at the time of diagnosis. Overall, 3969 (86.8\%) of case patients had ER status data available. Among those missing ER status, the pathology record indicated that the test had not been carried out for 153 cases, it had been ordered but was not available for 171 cases and the information was missing for 252 cases. An additional 30 cases had ER status listed as borderline and were also excluded from these analyses. We had PR information on 3795 women $(83.0 \%)$. An additional 179 were ordered but results were not available, 238 were not carried out and no information was available on 319. The PR status of 44 was borderline and these were excluded from the analyses. Both ER and PR status were available on 3771 cases, or $82.4 \%$. The percentage of participants with both ER and PR status available by site were: Atlanta $91.5 \%$, Detroit 70.3\%, Los Angeles 79.0\%, Philadelphia $72.3 \%$ and Seattle 93.5\%.

\section{Histology}

We conducted separate analyses by histology for 3455 ductal tumours (International Classification of Diseases for Oncology, ICD-O morphology code 8500), 274 lobular tumours (ICD-O morphology code 8520) and 261 mixed ductolobular tumours (ICD-O morphology code 8522). An additional 577 tumours of other histologies were not included in these analyses.

\section{Analyses}

We evaluated the following reproductive variables: gravidity (ever pregnant $v s$ never pregnant), parity (no full-term pregnancy $v s$ full-term pregnancy, defined as longer than 6 months $(>26$ weeks)), number of pregnancies, number of full-term pregnancies, age at first full-term pregnancy, years since last full-term pregnancy and duration of breastfeeding.

We excluded 21 women (seven cases and 14 controls) from the analyses because of unknown information on one or more pregnancy or breastfeeding variable These exclusions left us with 4668 controls and 3764 cases for the ERPR analyses. For the histology analyses, we excluded one additional case with missing parity and ERPR information. Thus, we ended up with 3990 cases for the histology analyses. A total of 11 women who had unknown ages at menarche were assigned the median age of 12 years and retained in all analyses.

For each stratum of ERPR status, we estimated odds ratios (ORs) and $95 \%$ confidence intervals (CIs) as measures of relative risk using unconditional logistic regression methods (Breslow and Day, 1980), while controlling for a number of potentially confounding 
variables that we had selected a priori. The following variables were included in all models: age (35-39, 40-44, 45-49, 50-54, $55-59,60-64$ years), race (White and African-American), family history of breast cancer (no first-degree family history, first-degree (mother, sister or daughter) family history, unknown or adopted), age at menarche $(\leqslant 11,12,13,>13$ years), study centre (five sites) and education ( $\leqslant$ high school, technical school or some college, college graduate). Where appropriate, we also adjusted for age at first full-term pregnancy $(\leqslant 19,20-24,25-29, \geqslant 30$ years) and number of full-term pregnancies $(1,2,3,4, \geqslant 5)$. For analyses of all women combined, we used never pregnant women as the reference group. For the analyses of age at first birth and total breastfeeding, we only included parous women. The reference group for total breastfeeding was parous women who had never breastfed. All adjustment variables were included as categorical variables in the models. We report the $P$-values from trend tests (Wald statistics) from the case-control analyses in the tables. All $P$-values reported are two-sided.

To determine whether the reproductive factors were associated equally with breast cancer of different receptor statuses, we excluded the controls, and defined $\mathrm{ER}+\mathrm{PR}+$ cases as 'cases' and $\mathrm{ER}-\mathrm{PR}$ - cases as 'controls'. We determined the ORs of being a receptor-positive case associated with the various reproductive factors, and estimated the tests for association or trend. A statistically significant test of association or trend (likelihood ratio test) from the case-case analysis suggested that the effect of the exposure factor differed by receptor status. A similar procedure was used for comparing $\mathrm{ER}+\mathrm{PR}$ - cases and $\mathrm{ER}-\mathrm{PR}+$ cases with ER-PR - cases, as well as for histology status, where we evaluated whether either lobular or ductolobular cancers differed from ductal tumours.

All analyses were performed using EPILOG (Epicenter Software, Pasadena, CA, USA) or the SAS statistical package (SAS Institute, Cary, NC, USA).

Study protocols were approved by the Institutional Review Boards at each participating centre.

\section{RESULTS}

Cases with data on ER and PR had fewer children $\left(\chi^{2} P=0.01\right)$, somewhat later age at first birth $(P=0.0001)$, and breastfed longer $(P=0.03)$ than those without data on ER and PR (Table 1). Table 2 shows the relative risk estimates of breast cancer associated with reproductive factors by hormone receptor status. In general, results for $\mathrm{ER}+\mathrm{PR}-$ and $\mathrm{ER}-\mathrm{PR}+$ tumours showed similar associations to ER $+\mathrm{PR}+$ tumours on all of the risk factors shown in the table ( $P$-values for all tests comparing $\mathrm{ER}+\mathrm{PR}+$, $\mathrm{ER}+\mathrm{PR}-$ and $\mathrm{ER}-\mathrm{PR}+$ receptor statuses $>0.10$, results not shown), we focus our presentation on the differences between the $\mathrm{ER}+\mathrm{PR}+$ and the ER-PR - cancers. Ever having had a full-term pregnancy was associated with a reduced $\mathrm{OR}$ for $\mathrm{ER}+\mathrm{PR}+$

Table I Distribution of reproductive factors among all 4567 breast cancer cases and among the 3764 cases with known tumour oestrogen receptor (ER) and progesterone receptor (PR) status and the 803 cases without known receptor status in the Women's Contraceptive and Reproductive Experiences (CARE) Study

\begin{tabular}{|c|c|c|c|c|c|c|c|}
\hline & \multicolumn{2}{|c|}{ All cases } & \multicolumn{2}{|c|}{ Cases with known ERPR status } & \multicolumn{2}{|c|}{ Cases without known ERPR status } & \multirow[b]{2}{*}{$\chi^{2} P$-value ${ }^{a}$} \\
\hline & $\mathbf{N}$ & $\%$ & $\mathbf{N}$ & $\%$ & $\mathbf{N}$ & $\%$ & \\
\hline Never pregnant & 588 & 12.9 & 502 & 13.3 & 86 & 10.7 & \\
\hline Pregnant but no full-term pregnancy & 299 & 6.6 & 249 & 6.6 & 50 & 6.2 & \\
\hline Ever full-term pregnancy & 3680 & 80.6 & 3013 & 80.1 & 667 & 83.1 & 0.11 \\
\hline Never pregnant & 588 & 12.9 & 502 & 13.3 & 86 & 10.7 & \\
\hline | r & 770 & 16.9 & 633 & 16.8 & 137 & 17.1 & \\
\hline 2 & |37| & 30.0 & 1153 & 30.6 & 218 & 27.2 & \\
\hline 3 & 841 & 18.4 & 680 & $|8|$. & 161 & 20.1 & \\
\hline 4 & 381 & 8.3 & 297 & 7.9 & 84 & 10.5 & \\
\hline $5+$ & 317 & 6.9 & 250 & 6.6 & 67 & 8.3 & 0.01 \\
\hline Pregnant but no full-term pregnancy & 299 & 6.6 & 249 & 6.6 & 50 & 6.2 & \\
\hline \multicolumn{8}{|l|}{ Parous women } \\
\hline \multicolumn{8}{|l|}{ Age at first full-term pregnancy } \\
\hline$\leqslant 19$ & 1044 & 28.4 & 806 & 26.8 & 238 & 35.7 & \\
\hline $20-24$ & 1367 & 37.2 & 1126 & 37.4 & 241 & 36.1 & \\
\hline $25-29$ & 777 & 21.1 & 667 & 22.1 & 110 & 16.5 & 0.0001 \\
\hline $30+$ & 492 & 13.4 & $4 \mid 4$ & 13.7 & 78 & 11.7 & \\
\hline \multicolumn{8}{|l|}{ Ever breastfeeding } \\
\hline No & 1653 & 44.9 & 1333 & 44.2 & 320 & 48.0 & \\
\hline Yes & 2027 & 55.1 & 1680 & 55.8 & 347 & 52.0 & 0.08 \\
\hline \multicolumn{8}{|l|}{ Ever breastfeeding at least 2 weeks } \\
\hline Never breastfeeding & 1653 & 44.9 & 1333 & 44.2 & 320 & 48.0 & \\
\hline Ever breastfeeding $<2$ weeks & |5 | & 4.1 & 123 & 4.1 & 28 & 4.2 & \\
\hline Ever breastfeeding $2+$ weeks & 1876 & 51.0 & 1557 & 51.7 & 319 & 47.8 & 0.19 \\
\hline \multicolumn{8}{|l|}{ Total breastfeeding (months) } \\
\hline 0 & 1653 & 44.9 & 1333 & 44.2 & 320 & 48.0 & \\
\hline$<1$ & 277 & 7.5 & 219 & 7.3 & 58 & 8.7 & \\
\hline $1-6$ & 820 & 22.3 & 699 & 23.2 & 121 & 18.1 & \\
\hline $7-23$ & 663 & 18.0 & 550 & 18.3 & 113 & 16.9 & \\
\hline $24+$ & 267 & 7.3 & 212 & 7.0 & 55 & 8.3 & 0.03 \\
\hline
\end{tabular}

${ }^{a} \chi^{2} P$-value for the difference between the cases with known and the cases without known ERPR status. 
Table 2 Odds ratios $(\mathrm{OR})^{\mathrm{a}}$ and $95 \%$ confidence intervals $(\mathrm{Cl})$ of breast cancer of different receptor status associated with reproductive factors

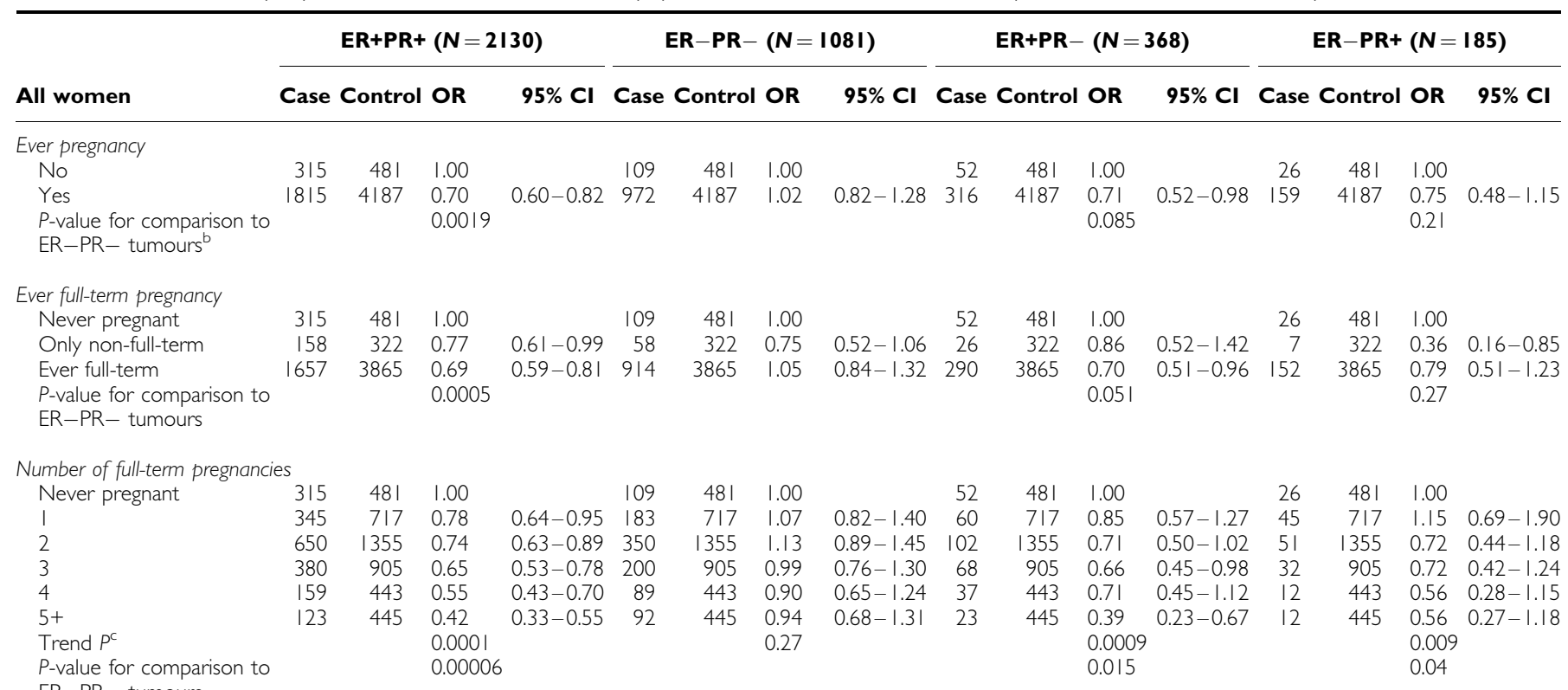

$E R+P R+(N=1657)$

$E R-P R-(N=914)$

$E R+P R-(N=290)$

$\mathrm{ER}-\mathrm{PR}+(\mathrm{N}=152)$

Parous only

Case Control OR

95\% Cl Case Control OR

95\% Cl Case Control OR

95\% Cl Case Control OR $95 \% \mathrm{Cl}$

Age at first full-term pregnancy

$20-24$

$25-29$

$30+$

Trend $P$

$P$-value for comparison to

$391 \quad 1190 \quad 1.00$

$\begin{array}{lll}639 & 1460 & 1.16\end{array}$

$\begin{array}{lll}392 & 718 & 1.44\end{array}$

$\begin{array}{lll}235 & 497 & 1.22\end{array}$

0.01

0.07

ER-PR - tumours

Years since last full-term pregnancy

$\begin{array}{rrrr}10+ & 1121 & 2625 & 1.00\end{array}$

$7-9$

$3-6$

$<3$

Trend $P$

$\begin{array}{lll}85 & 184 & 1.21 \\ 78 & 200 & 1.03\end{array}$

$\begin{array}{lll}78 & 200 & 1.03 \\ 25 & 127 & 0.55\end{array}$

$\begin{array}{ll}P \text {-value for comparison to } & 0.15 \\ & 0.64\end{array}$

ER-PR - tumours

$\begin{array}{rrrrr} & 303 & 1190 & 1.00 & \\ 0.99-1.36 & 314 & 1460 & 0.92 & 0.76 \\ 1.19-1.75 & 184 & 718 & 1.06 & 0.84 \\ 0.97-1.54 & 113 & 497 & 0.91 & 0.68 \\ & & & 0.85 & \end{array}$

$\begin{array}{rrrr}67 & 1190 & 1.00 \\ 0.76-1.10 & 127 & 1460 & 1.32\end{array}$

$\begin{array}{llll}0.84-1.34 & 58 & 718 & 1.23\end{array}$

$\begin{array}{llll}0.68-1.22 & 38 & 497 & 1.14\end{array}$

1.14
0.59

0.66

$\begin{array}{lrrrr} & 45 & 1190 & 1.00 & \\ 0.95-1.83 & 46 & 1460 & 0.85 & 0.54-1.32 \\ 0.81-1.86 & 33 & 718 & 1.15 & 0.69-1.94 \\ 0.70-1.87 & 28 & 497 & 1.17 & 0.64-2.12 \\ & & & 0.45 & \\ & & & 0.29 & \end{array}$

$\begin{array}{rrrr} & 584 & 2625 & 1.00 \\ 0.88-1.66 & 53 & 184 & 0.95 \\ 0.73-1.46 & 54 & 200 & 0.86 \\ 0.33-0.91 & 37 & 127 & 0.87 \\ & & & 0.46\end{array}$

$\begin{array}{rrrr} & 198 & 2625 & 1.00 \\ 0.66-1.38 & 12 & 184 & 1.47 \\ 0.58-1.28 & 12 & 200 & 1.55 \\ 0.54-1.40 & 6 & 127 & 1.35 \\ & & & 0.32 \\ & & & 0.17\end{array}$

$\begin{array}{rrrrr} & 84 & 2625 & 1.00 & \\ 0.72-3.00 & 5 & 184 & 0.55 & 0.20-1.50 \\ 0.72-3.34 & 7 & 200 & 0.73 & 0.28-1.85 \\ 0.49-3.72 & 9 & 127 & 1.42 & 0.55-3.66 \\ & & & 0.75 & \\ & & & 0.60 & \end{array}$

Ever breastfeeding

$\begin{array}{llll}\text { No } & 717 & 1533 & 1.00 \\ \text { Yes } & 940 & 2332 & 0.78\end{array}$

$P$-value for comparison to

$\begin{array}{lll}940 & 2332 & 0.78 \\ & & 0.84\end{array}$

ER-PR - tumours

$\begin{array}{lllllllllllll} & 422 & 1533 & 1.00 & & 130 & 1533 & 1.00 & & 64 & 1533 & 1.00 & \\ 0.69-0.89 & 492 & 2332 & 0.78 & 0.66-0.91 & 160 & 2332 & 0.80 & 0.61-1.03 & 88 & 2332 & 0.92 & 0.64-1.32\end{array}$

Ever breastfeeding at least 2 weeks

$\begin{array}{llll}\text { Never breastfeeding } & 717 & 1533 & 1.00\end{array}$

$\begin{array}{llll}\text { Only }<2 \text { weeks } & 65 & 150 & 0.94\end{array}$

$\begin{array}{llll}\text { Ever } 2+\text { weeks } & 875 & 2182 & 0.77\end{array}$

$P$-value for comparison to

0.91

$\begin{array}{lrrr}422 & 1533 & 1.00\end{array}$

$\begin{array}{llll}130 & 1533 & 1.00\end{array}$

$150 \quad 0.94$

$0.65-1.37 \quad 9$

$150 \quad 0.74$

$\begin{array}{ll}2182 & 0.80 \\ 0.75\end{array}$

$\begin{array}{llll}64 & 1533 & 1.00\end{array}$

$\begin{array}{lllll}0.36-1.49 & 9 & 150 & 1.33 & 0.64-2.76\end{array}$

ER-PR - tumours

Total breastfeeding (month)

0

$1-6$

$7-23$

24+

Trend $P$

$\begin{array}{rrr}717 & 1533 & 1.00 \\ 123 & 306 & 0.85\end{array}$

$\begin{array}{lll}123 & 306 & 0.85 \\ 376 & 902 & 0.78\end{array}$

$\begin{array}{lll}323 & 775 & 0.79\end{array}$

$\begin{array}{lll}118 & 349 & 0.69\end{array}$

$P$-value for comparison to

ER-PR-$$
0.68-0.88 \quad 452
$$

${ }^{\mathrm{a}}$ ORs are adjusted for categorical variables of age, race, family history of breast cancer, age at menarche, education and study site (see text). ${ }^{b}$-value for a test for association or trend (likelihood ratio test) from case-case analyses where 'controls' represent ER-PR- cases (see text). 'P-value from a test for trend (Wald statistic) from case-control analyses. ${ }^{\mathrm{d}}$ ORs for parous women are also adjusted for number of full-term pregnancies and age at first full-term pregnancy. ${ }^{\mathrm{e}}$ Analyses for years since last full-term pregnancy restricted to women with $2+$ full-term pregnancies. 
tumours (OR 0.69, 95\% CI 0.59-0.81), while no such effect was observed for ER-PR - tumours (OR 1.05, 95\% CI 0.84-1.32, P comparing cases by ERPR status $=0.0005)$. Being multiparous was associated with reduced ORs of ER $+\mathrm{PR}+$ tumours, but not of $\mathrm{ER}-\mathrm{PR}-$ tumours $(P$ comparing cases by ERPR status $=0.00006)$, with five or more full-term pregnancies conferring an estimated $58 \%$ reduction in risk of $\mathrm{ER}+\mathrm{PR}+$ tumours.

Among parous women, older ages at first birth were associated with modest increases in relative risk estimates of $\mathrm{ER}+\mathrm{PR}+$ tumours, but not ER-PR - tumours, although the test comparing receptor status did not achieve statistical significance $(P=0.07)$.

On the other hand, the effects of breastfeeding did not differ by receptor status. Among parous women, the relative risk estimates for both $\mathrm{ER}+\mathrm{PR}+$ and $\mathrm{ER}-\mathrm{PR}$ - tumours were statistically significantly reduced among those who had breastfed compared to those who had not. The effect of total duration of breastfeeding was remarkably similar for both $\mathrm{ER}+\mathrm{PR}+$ and $\mathrm{ER}-\mathrm{PR}-$ tumours. Compared to women who never breastfed, women who breastfed 24 months or longer were at an estimated 31 and 35\% lower relative risk of $\mathrm{ER}+\mathrm{PR}+$ and $\mathrm{ER}-\mathrm{PR}-$ tumours, respectively ( $P$ comparing cases by ERPR status $=0.71$ ).

Table 3 shows the OR per full-term pregnancy as well as the OR per 12 months of breastfeeding by receptor status in different subgroups of women. The results were similar when we restricted the analyses to White women or to African-American women, or when analyses were restricted to specific race-age subgroups. The only exception was in White women under age 50 where multiparity was associated with a statistically significant relative risk reduction for both receptor-positive and -negative tumours (results not shown).

\section{Histology}

In Table 4, we show the effect of reproductive factors on tumours of ductal, ductolobular and lobular histology. Ever having had a full-term pregnancy was associated with an OR of 0.80 (95\% CI $0.69-0.92)$ for ductal tumours, OR of 0.89 (95\% CI
$0.60-1.33)$ for lobular tumours and OR of 0.65 (95\% CI $0.45-0.93$ ) for ductolobular cancers. Increasing number of full-term pregnancies was associated with a strong protective effect for ductal tumours ( $P$ for trend $=0.00001)$ and for ductolobular tumours ( $P$ for trend $=0.001$ ). There was no significant protective trend for lobular tumours $(P=0.19)$, but having had four or more pregnancies was associated with an $\mathrm{OR}$ of 0.56 , similar to the OR of 0.62 for ductal tumours and 0.43 for ductolobular tumours. The tests comparing tumours of other histologies with ductal tumours were not statistically significant (all $P$-values $=0.20$ or higher)

Women with later age at first full-term pregnancy were at higher relative risk of lobular tumours than women with a first full-term pregnancy before age $20(P$ for trend $=0.02)$; this was not observed for ductal ( $P$ for trend $=0.32$ ) or ductolobular tumours ( $P$ for trend $=0.92)$. The test for comparing lobular and ductal cancer cases did not reach statistical significance $(P=0.11)$.

Total duration of breastfeeding showed slightly stronger risk reductions for ductal than for either ductolobular or lobular cancers, and was statistically significant only for ductal tumours. However, the number of women with long duration of breastfeeding was small in the lobular and ductolobular groups, and the tests comparing lobular or ductolobular to ductal tumours were not statistically significant.

When we did further analyses of tumours of different histologies across different age and ethnic groups, the results were consistent with those reported above (results not shown). When analyses were limited to White women above age 50 with $\mathrm{ER}+\mathrm{PR}+$ tumours, the only subgroup defined by age, race and receptor status for which there were sufficient number of subjects to analyse histology, the difference between ductolobular and ductal tumours reached marginal statistical significance (OR per FTP for ductal tumours 0.92 (95\% CI $0.86-0.99)$ and OR for ductolobular tumours 0.78 (95\% CI $0.65-0.93), P=0.05)$. We observed no statistically significant differences in the relative risks estimates for 12 months of breastfeeding between tumours of the different histologic subtypes (results not shown).

Table 3 Adjusted odds ratios $(\mathrm{OR})^{\mathrm{a}}$ and $95 \%$ confidence intervals $(\mathrm{Cl})$ per full-term pregnancy (FTP) and 12 months breastfeeding by oestrogen and progesterone receptor (ERPR) status

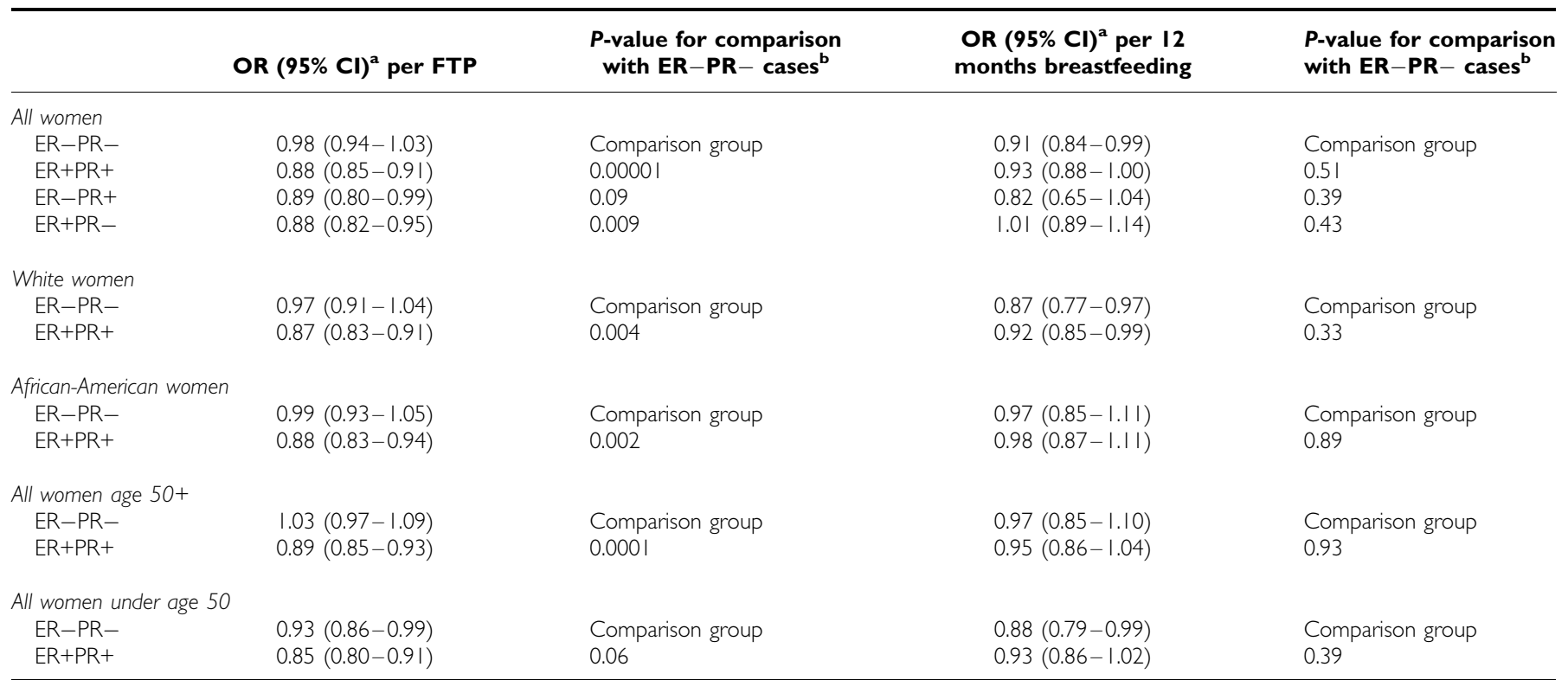

${ }^{a}$ ORs are adjusted for categorical variables of age, race, family history of breast cancer, age at menarche, education and study site (see text). Women with non-full-term pregnancies were not included in these analyses. Only parous women were included in the analyses of breastfeeding. ${ }^{b} P$-value for a test for trend from a case-case analyses where 'cases' represent ER+PR+ cases (see text). 
Table 4 Adjusted odds ratios $(\mathrm{ORs})^{\mathrm{a}}$ and $95 \%$ confidence intervals $(\mathrm{Cl})$ of breast cancer of different histology associated with reproductive factors

\begin{tabular}{|c|c|c|c|c|c|c|c|c|c|c|c|c|}
\hline \multirow[b]{2}{*}{ All women } & \multicolumn{4}{|c|}{ Ductal $(N=3455)$} & \multicolumn{4}{|c|}{ Lobular $(N=274)$} & \multicolumn{4}{|c|}{ Ductolobular $(N=26 \mathrm{I})$} \\
\hline & Case & Control & OR & $95 \% \mathrm{Cl}$ & Case & Control & OR & $95 \% \mathrm{Cl}$ & Case & Control & OR & $95 \% \mathrm{Cl}$ \\
\hline \multicolumn{13}{|l|}{ Ever pregnancy } \\
\hline No & 441 & 481 & 1.00 & & 31 & 481 & 1.00 & & 41 & 481 & 1.00 & \\
\hline Yes & 3014 & 4187 & 0.79 & $0.69-0.91$ & 243 & 4187 & 0.91 & $0.61-1.35$ & 220 & 4188 & 0.66 & $0.46-0.94$ \\
\hline P-value for comparison to ductal tumours ${ }^{\mathrm{b}}$ & & & & & & & 0.47 & & & & 0.34 & \\
\hline$P$-value for comparison to ductolobular tumours ${ }^{c}$ & & & & & & & 0.28 & & & & & \\
\hline \multicolumn{13}{|l|}{ Ever full-term pregnancy } \\
\hline Never pregnant & 441 & 481 & 1.00 & & 31 & 481 & 1.00 & & 41 & 481 & 1.00 & \\
\hline Only non-full-term pregnancy & 220 & 322 & 0.74 & $0.60-0.92$ & 20 & 322 & 1.09 & $0.60-1.96$ & 20 & 322 & 0.75 & $0.43-1.31$ \\
\hline Ever full-term pregnancy & 2794 & 3865 & 0.80 & $0.69-0.92$ & 223 & 3865 & 0.89 & $0.60-1.33$ & 200 & 3866 & 0.65 & $0.45-0.93$ \\
\hline$P$-value for comparison to ductal tumours & & & & & & & 0.55 & & & & 0.30 & \\
\hline$P$-value for comparison to ductolobular tumours & & & & & & & 0.30 & & & & & \\
\hline \multicolumn{13}{|l|}{ Number of full-term pregnancies } \\
\hline $4+$ & 525 & 888 & 0.62 & $0.52-0.74$ & 38 & 888 & 0.56 & $0.33-0.93$ & 31 & 889 & 0.43 & $0.26-0.71$ \\
\hline Trend $P^{d}$ & & & 0.00001 & & & & 0.19 & & & & 0.001 & \\
\hline$P$-value for comparison to ductal tumours & & & & & & & 0.35 & & & & 0.24 & \\
\hline$P$-value for comparison to ductolobular tumours & & & & & & & 0.20 & & & & & \\
\hline
\end{tabular}

Ductal $(\mathbf{N}=\mathbf{2 7 9 4})$

Lobular $(\mathbf{N}=\mathbf{2 2 3})$

Ductolobular $(\mathbf{N}=\mathbf{2 0 0})$

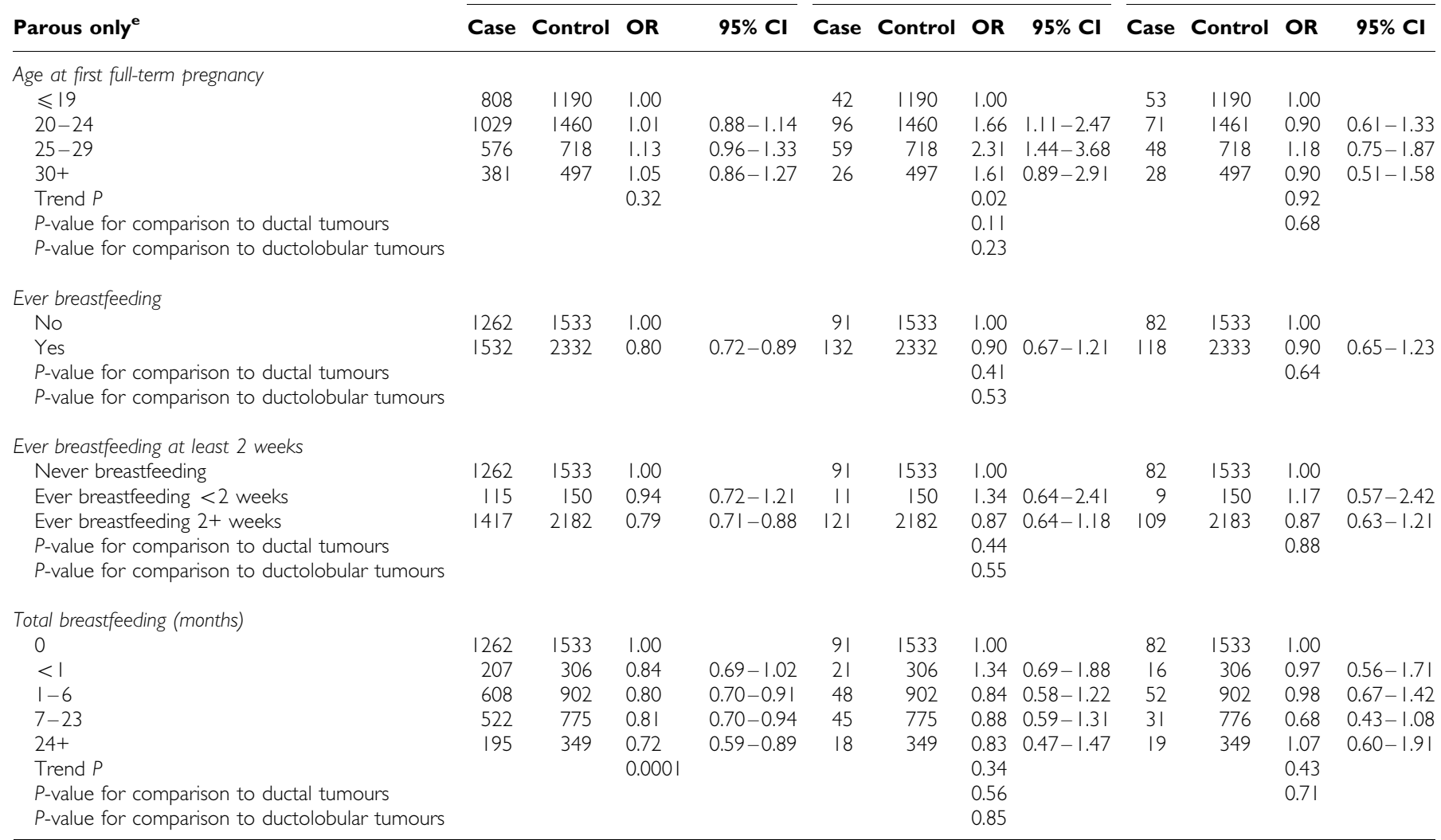

${ }^{a}$ ORs are adjusted for categorical variables of age, race, family history of breast cancer, age at menarche, education and study site (see text). ${ }^{\mathrm{b}} \mathrm{P}$-value for a test for association or trend (likelihood ratio test) from a case-case analyses where 'cases' represent cases with ductal tumours (see text). 'P $P$-value for a test for association or trend (likelihood ratio test) from a case-case analyses where 'cases' represent cases with ductolobular tumours. ${ }^{\text {d }} P$-value from a test for trend (Wald statistic) from case-control analyses. ${ }^{e} \mathrm{ORs}$ for parous women are also adjusted for number of full-term pregnancies and age at first full-term pregnancy.

When analyses were restricted to women who had never used hormone therapy, the results were very similar, with no differences between the relative risk estimates of the different histologic types for either full-term pregnancy or breastfeeding.

\section{DISCUSSION}

Our recent evaluation of reproductive factors from the CARE study (Ursin et al, 2004) found that the effects of reproductive factors 
were in general very similar in African-American and White women. In particular, parity and lactation had similar protective effects in the two racial groups.

In the present analyses, we found that multiparity and early age at first birth were associated with reduced relative risk of $\mathrm{ER}+\mathrm{PR}+$ tumours, but not of $\mathrm{ER}-\mathrm{PR}-$ tumours. The relative risk reduction observed with duration of breastfeeding did not differ between receptor-negative and -positive tumours. Our results were consistent across subgroups of women based on their age and ethnicity.

Previous studies of the effects of parity or age at first full-term pregnancy (or age at first birth) on tumours of different receptor statuses have been mixed. Two studies found similar effects of parity on receptor-positive and -negative tumours (Yoo et al, 1997; Britton et al, 2002). One study suggested a protective effect of multiparity on $\mathrm{ER}+\mathrm{PR}+$ tumours, but not receptor-negative tumours; however, tests comparing these tumour types were not statistically significant, possibly because of few $(n=80)$ ER-PRcases (Potter et al, 1995). Another study found similar effects of parity on receptor-positive and -negative tumours among postmenopausal women (Cotterchio et al, 2003), while among premenopausal women, the inverse association with parity was only observed for ER $+\mathrm{PR}+$ cases. Only one of these previous studies had a sample size greater than ours (Cotterchio et al, 2003), but that study had a broader age range (25-74 years), and all results were presented separately for pre- and postmenopausal women. Thus, lack of statistical power in these previous studies may explain why results from our study are only partially consistent with them.

Several studies have addressed the effect of age at first birth on receptor status of breast tumours (Potter et al, 1995; Yoo et al, 1997; Huang et al, 2000; Britton et al, 2002; Cotterchio et al, 2003). Consistent with our findings, three of these studies found evidence that late age at first birth was associated with receptor-positive tumours only (Potter et al, 1995; Huang et al, 2000; Cotterchio et al, 2003). Our results on breastfeeding are also consistent with the few previous studies that have addressed this (Hildreth et al, 1983; McTiernan et al, 1986; Cooper et al, 1989; Yoo et al, 1997; Huang et al, 2000; Britton et al, 2002; Cotterchio et al, 2003).

We had few women with ER-PR + and ER + PR - tumours, but, in general, results for these tumours were similar to those for ER + PR + tumours. Previous reports have not drawn strong conclusions on the associations between these subtypes and reproductive factors (Huang et al, 2000; Britton et al, 2002). It is possible that some of the similarity between $\mathrm{ER}+\mathrm{PR}+$ and $\mathrm{ER}-\mathrm{PR}+$ tumours is due to some $\mathrm{ER}+\mathrm{PR}+$ tumours that are misclassified as ER-PR + (Horwitz, 1988). By using the combined status of ER and PR, we reduce the problem of including any tumours where one of the receptor statuses was mislabelled.

The finding of a protective effect of pregnancies only on receptor-positive tumours support the evidence suggesting that pregnancies protect against breast cancer primarily through hormonal mechanisms. Pregnancies have been found to reduce plasma levels of oestrogen (oestrone, oestradiol and oestriol) (Bernstein et al, 1985; Garcia-Closas et al, 2002) and follicular phase levels of progesterone (Garcia-Closas et al, 2002), increase levels of sex hormone-binding globulin (Bernstein et al, 1985) and modify the oestrogen changes that occur with age (Dorgan et al, 1995). Either as a consequence of these changes or of other pregnancy changes, the resulting breast changes are characterised by further differentiation of the terminal duct lobular units (Russo et al, 1992).

Lactation has also been proposed to protect against breast cancer through hormonal mechanisms by postponing the resumption of ovulatory menstrual cycles after a pregnancy, by increasing the differentiation of breast tissue (Russo and Russo, 1994) or by altering oestrogen levels in the breast (Petrakis et al, 1987). In addition, it has been proposed that lactation also has a direct mechanical effect by which carcinogenic agents are excreted from the breast ductal tissue (Murrell, 1991). Our findings suggest that the effect of lactation may not be hormonal, or that at least the mechanisms for this protection are different from those for pregnancies. For instance, the effect of lactation could still be through hormonal mechanisms if lactation exerts its effect at a time period prior to when the hormonal receptor status of a future tumour is developing.

We found few differences between lobular and ductal tumours. Increasing parity had a greater impact on ductal and ductolobular tumours than on lobular tumours, but age at first full-term pregnancy was slightly more protective against lobular cancers. Thus, overall reproductive factors seem to protect against all three histological types. In general, the findings for ductolobular tumours were more similar to ductal than to lobular tumours. These findings are consistent with a recent gene expression study (Zhao et al, 2004), which found that about half of the lobular cancers had similar gene expression patterns to ductal tumours, while the remaining 'typical' lobular cancers had a different gene expression pattern. However, in these analyses we found little evidence that these reproductive factors act differently on either ductal or lobular tumours, with the possible exception that early age at first birth was most strongly associated with lower risk of lobular cancers, and that ductolobular tumours were associated with the strongest risk reduction per full-term pregnancy.

Although some evidence exists that lobular tumours are more strongly associated with hormonal risk factors such as postmenopausal hormone use and oral contraceptive use ( $\mathrm{Li}$ et al, 2000; Daling et al, 2002) than ductal tumours, this has not been found in all studies (Ursin et al, 2002). Further, one study found that early age at menarche, late age at menopause and obesity are more strongly associated with ductal tumours than lobular tumours ( $\mathrm{Li}$ et al, 2003). Our study suggests that ductolobular tumours should either be treated as a separate entity or combined with ductal cancers, but should not be combined with lobular cancers. Further, given the confounding effect of receptor status, studies of histology should also separate tumours by receptor status of tumour.

One limitation of our study is that we used ERPR status as it was reported in the pathology report. Although we presume the majority of cases were assessed by immunohistochemistry, we have no data on the methods used by each laboratory. It is possible that some laboratories used different methods, or that the cutoff for a positive receptor status varied between laboratories. It is also possible that the methods varied geographically, by site. We did adjust all analyses for study site and believe it unlikely that this caused any of the observed associations, and that the most likely effect, if any, would have been to bias our relative risk estimates towards the null value.

Another weakness is that ERPR status was not available for all cases. The frequency of unknown receptor status in our study $(17.6 \%)$ is remarkably similar to that reported by a prior study conducted within the SEER registries (Chu and Anderson, 2002). In that study of 123732 tumours, 18\% were unknown and 5\% were not carried out. The reason for the large number of unknowns is unclear, as is the information on the true distribution of ERPR status among those reported as unknown (Chu and Anderson, 2002). Even though the CARE cases with no ERPR status were more likely to be multiparous, give birth early and have breastfed shorter, we think it is unlikely that receptor information on these cases would have altered the results in our study.

In conclusion, high parity and early age at first birth were associated with a reduction in risk only for $\mathrm{ER}+\mathrm{PR}+$ tumours. Breastfeeding was associated with a reduction in risk for both $\mathrm{ER}+\mathrm{PR}+$ and ER-PR - tumours. Combined with previous research, this suggests that parity and age at first birth act through different mechanisms than breastfeeding. All reproductive factors showed similar associations with both ductal, ductolobular and 
lobular tumours, suggesting that these tumours have similar aetiologies.

\section{ACKNOWLEDGEMENTS}

This study was supported by the National Institute of Child Health and Human Development, with additional support from the National Cancer Institute, through contracts with Emory
University (N01 HD 3-3168), Fred Hutchinson Cancer Research Center (N01 HD 2-3166), Karmanos Cancer Institute at Wayne State University (N01 HD 3-3174), University of Pennsylvania (N01 HD-3-3176) and University of Southern California (N01 HD 3-3175), and through an intra-agency agreement with the Centers for Disease Control and Prevention (Y01 HD 7022). General support through SEER Contract Numbers N01-PC-67006 (Atlanta), N01-CN-65064 (Detroit), N01-CN-67010 (Los Angeles) and N01-CN-0532 (Seattle) is also acknowledged.

\section{REFERENCES}

Bernstein L, Pike MC, Ross RK, Judd HL, Brown JB, Henderson BE (1985) Estrogen and sex hormone-binding globulin levels in nulliparous and parous women. J Natl Cancer Inst 74: 741 - 745

Breslow NE, Day NE (1980) Statistical Methods in Cancer Research. Volume 1 - The Analysis of Case - Control Studies. Lyon: International Agency for Research on Cancer

Britton JA, Gammon MD, Schoenberg JB, Stanford JL, Coates RJ, Swanson CA, Potischman N, Malone KE, Brogan DJ, Daling JR, Brinton LA (2002) Risk of breast cancer classified by joint estrogen receptor and progesterone receptor status among women 20-44 years of age. Am J Epidemiol 156: $507-516$

Chu KC, Anderson WF (2002) Rates for breast cancer characteristics by estrogen and progesterone receptor status in the major racial/ethnic groups. Breast Cancer Res Treat 74: 199-211

Collaborative Group on Hormonal Factors in Breast Cancer (2002) Breast cancer and breastfeeding: collaborative reanalysis of individual data from 47 epidemiological studies in 30 countries, including 50302 women with breast cancer and 96973 women without the disease. Lancet 360: $187-195$

Cooper JA, Rohan TE, Cant EL, Horsfall DJ, Tilley WD (1989) Risk factors for breast cancer by oestrogen receptor status: a population-based case control study. Br J Cancer 59: 119-125

Cotterchio M, Kreiger N, Theis B, Sloan M, Bahl S (2003) Hormonal factors and the risk of breast cancer according to estrogen- and progesteronereceptor subgroup. Cancer Epidemiol Biomarkers Prev 12: 1053-1060

Daling JR, Malone KE, Doody DR, Voigt LF, Bernstein L, Coates RJ, Marchbanks PA, Norman SA, Weiss LK, Ursin G, Berlin JA, Burkman RT, Deapen D, Folger SG, McDonald JA, Simon MS, Strom BL, Wingo PA, Spirtas R (2002) Relation of regimens of combined hormone replacement therapy to lobular, ductal, and other histologic types of breast carcinoma. Cancer 95: 2455-2464

Dorgan JF, Reichman ME, Judd JT, Brown C, Longcope C, Schatzkin A, Campbell WS, Franz C, Kahle L, Taylor PR (1995) Relationships of age and reproductive characteristics with plasma estrogens and androgens in premenopausal women. Cancer Epidemiol Biomarkers Prev 4: 381-386

Enger SM, Ross RK, Paganini-Hill A, Carpenter CL, Bernstein L (2000) Body size, physical activity, and breast cancer hormone receptor status: results from two case-control studies. Cancer Epidemiol Biomarkers Prev 9: 681-687

Garcia-Closas M, Herbstman J, Schiffman M, Glass A, Dorgan JF (2002) Relationship between serum hormone concentrations, reproductive history, alcohol consumption and genetic polymorphisms in premenopausal women. Int J Cancer 102: 172-178

Hildreth NG, Kelsey JL, Eisenfeld AJ, LiVolsi VA, Holford TR, Fischer DB (1983) Differences in breast cancer risk factors according to the estrogen receptor level of the tumor. J Natl Cancer Instit 70: 1027-1031

Horwitz KB (1988) The central role of progesterone receptors and progestational agents in the management and treatment of breast cancer. Semin Oncol 15: 14-19

Huang WY, Newman B, Millikan RC, Schell MJ, Hulka BS, Moorman PG (2000) Hormone-related factors and risk of breast cancer in relation to estrogen receptor and progesterone receptor status. Am J Epidemiol 151: $703-714$
Kelsey JL, Gammon MD, John EM (1993) Reproductive factors and breast cancer. Epidemiol Rev 15: 36-47

Li CI, Malone KE, Porter PL, Weiss NS, Tang MT, Cushing-Haugen KL, Daling JR (2003) Relationship between long durations and different regimens of hormone therapy and risk of breast cancer. JAMA 289: $3254-3263$

Li CI, Weiss NS, Stanford JL, Daling JR (2000) Hormone replacement therapy in relation to risk of lobular and ductal breast carcinoma in middle-aged women. Cancer 88: 2570-2577

Marchbanks PA, McDonald JA, Wilson HG, Burnett NM, Daling JR, Bernstein L, Malone KE, Strom BL, Norman SA, Weiss LK, Liff JM, Wingo PA, Burkman RT, Folger SG, Berlin JA, Deapen DM, Ursin G, Coates RJ, Simon MS, Press MF, Spirtas R (2002) The NICHD Women's Contraceptive and Reproductive Experiences study: methods and operational results. Ann Epidemiol 12: 213-221

McTiernan A, Thomas DB, Johnson LK, Roseman D (1986) Risk factors for estrogen receptor-rich and estrogen receptor-poor breast cancers. J Natl Cancer Inst 77: 849-854

Murrell TG (1991) Epidemiological and biochemical support for a theory on the cause and prevention of breast cancer. Med Hypotheses 36: $389-396$

Petrakis NL, Wrensch MR, Ernster VL, Miike R, Murai J, Simberg N, Siiteri PK (1987) Influence of pregnancy and lactation on serum and breast fluid estrogen levels: implications for breast cancer risk. Int J Cancer 40: $587-591$

Potter JD, Cerhan JR, Sellers TA, McGovern PG, Drinkard C, Kushi LR, Folsom AR (1995) Progesterone and estrogen receptors and mammary neoplasia in the Iowa Women's Health Study: how many kinds of breast cancer are there? Cancer Epidemiol Biomarkers Prev 4: 319-326

Russo J, Rivera R, Russo IH (1992) Influence of age and parity on the development of the human breast. Breast Cancer Res Treat 23: 211-218

Russo J, Russo IH (1994) Toward a physiological approach to breast cancer prevention. Cancer Epidemiol Biomarkers Prev 3: 353-364

Stanford JL, Szklo M, Boring CC, Brinton LA, Diamond EA, Greenberg RS, Hoover RN (1987) A case-control study of breast cancer stratified by estrogen receptor status. Am J Epidemiol 125: 184-194

Ursin G, Bernstein L, Wang Y, Lord SJ, Deapen D, Liff JM, Norman SA, Weiss LK, Daling JR, Marchbanks PA, Malone KE, Folger SG, McDonald JA, Burkman RT, Simon MS, Strom BL, Spirtas R (2004) Reproductive factors and risk of breast carcinoma in a study of White and AfricanAmerican women. Cancer 101: 353-362

Ursin G, Tseng CC, Paganini-Hill A, Enger S, Wan PC, Formenti S, Pike MC, Ross RK (2002) Does menopausal hormone replacement therapy interact with known factors to increase risk of breast cancer? J Clin Oncol 20: $699-706$

Yoo KY, Tajima K, Miura S, Takeuchi T, Hirose K, Risch H, Dubrow R (1997) Breast cancer risk factors according to combined estrogen and progesterone receptor status: a case-control analysis. Am J Epidemiol 146: $307-314$

Zhao H, Langerod A, Ji Y, Nowels KW, Nesland JM, Tibshirani R, Bukholm IK, Karesen R, Botstein D, Borresen-Dale AL, Jeffrey SS (2004) Different gene expression patterns in invasive lobular and ductal carcinomas of the breast. Mol Biol Cell 19: 19 